\title{
Breaking from Tradition: Transforming Leadership Education in Nursing
}

Holly J. Symonds-Brown

MacEwan University, symondsh@macewan.ca

Margaret F. Milner

MacEwan University, milnerm0@macewan.ca

Follow this and additional works at: https://qane-afi.casn.ca/journal

\section{Recommended Citation}

Symonds-Brown, Holly J. and Milner, Margaret F. (2015) "Breaking from Tradition: Transforming Leadership Education in Nursing," Quality Advancement in Nursing Education - Avancées en formation infirmière: Vol. 1: Iss. 3, Article 2. DOI: https://doi.org/10.17483/2368-6669.1041

This Article is brought to you for free and open access by Quality Advancement in Nursing Education - Avancées en formation infirmière. It has been accepted for inclusion in Quality Advancement in Nursing Education - Avancées en formation infirmière by an authorized editor of Quality Advancement in Nursing Education - Avancées en formation infirmière. 


\section{Breaking from Tradition: Transforming Leadership Education in Nursing}

\section{Cover Page Footnote}

We would like to acknowledge the valuable contributions made by the NURS 479 course team in the BScN program at MacEwan University in the development of this manuscript. 
Visioning nursing curricula that effectively prepares undergraduate nursing students for professional nursing practice in an ever-changing health care system continues to challenge educators. Leadership development among practicing nurses is critical for nurses to be engaged in health system reform and transformation (Canadian Nurses Association, 2009; Canadian Association of Schools of Nursing [CASN], 2014; International Council of Nurses, 2015). According to Keighley (2013), the notion of education programs "future proofing" nurses to allow for flexibility in role and work contexts is also crucial. Preparing graduates with the knowledge and skills required to engage as active leaders and team members within health care systems requires a break from traditional nursing curriculum design (Benner, 2010; MacMillan, 2013). This article describes the development and implementation of an innovative clinical course wherein undergraduate nursing students are provided opportunities to explore and further develop their leadership acumen within an undergraduate nursing curriculum. Breaking from curricular tradition requires intentional use of pedagogy, innovative instructional design, and formation of collaborative partnerships. We highlight the impact of this journey on stakeholders and identify challenges and implications for future research.

\section{Literature Review}

\section{Leadership Education: Historical Evolution}

Whereas traditional nursing entry-to practice-competencies focused on the development of clinical judgment and reasoning skills, there is now a clearly identified need for new graduates with a broader repertoire of skills (CASN, 2014; Institute of Medicine, 2011). In order for nurses to be engaged in health care system design, advocacy, and stewardship, nurses entering the field must have knowledge of complex systems, political/economic forces influencing populations, and structural views of health (CASN, 2014; National Expert Commission, 2012). As global health care costs continue to spiral out of control, we need nursing leadership now more than ever to improve the health status of populations in a globalized world (International Council of Nurses, 2015). Cummings et al. (2010) argue that the positional view of leadership and tradition of professional maturity leading to leadership competency is no longer sufficient for the complex health systems nurses work within. Relational, team-based transformative approaches to leadership have been found to be much more successful at creating high-functioning nursing units (Cummings et al., 2010; Hewison \& Morrell, 2013; Pollard \& Wild, 2014). Patient safety research has also reinforced the need for leadership that engages health care teams in evidenceinformed and safe practices (Leonard \& Frankel, 2011; Teamwork \& Communication Working Group, 2011). Both the American Association of Colleges of Nursing (2008) and the Canadian Association of Schools of Nursing (2014) have moved toward requiring leadership as a competency included in undergraduate curricula. A nursing curricular response is paramount (MacMillan, 2013), yet research and actual inventories of approaches used within undergraduate programs are scare and the mores that influence curricular traditions are well entrenched (Anthony \& Landeen, 2009; Hewison \& Morrel, 2013).

The inclusion of leadership education within nursing curriculum has traditionally been seen as a "stand alone" senior theory course often conflated with management competencies (Jones \& Sackett, 2009; Lemire, 2005). Clinical practica within nursing curriculum often involve providing direct care or related observation experiences, and serve as an opportunity for students to integrate theoretical knowledge into practice (Waite, McKinney, Smith-Glasglow, \& Meloy, 2014). Benner (2010) has encouraged nursing educators to consider the integration of experiential and active learning strategies in all areas of nursing curriculum. Interestingly, 
through an environmental scan of Canadian nursing program curricula, outward appearances suggest that while traditional theory courses in nursing curriculum include opportunities for application in practice, the use of leadership practica in undergraduate programs is almost nonexistent. The resulting question is then how new graduates translate the theoretical understanding related to leadership and health system design and transformation into actual practice. Is it something that can be afforded to be kept on the fringes of nursing education hoping the seeds planted from theory courses blossom on their own, or do nurse educators have a responsibility to provide a space for students to practice the cognitive, relational, and meaning-making skills required for leadership development?

\section{Innovation in Leadership Education}

Reviewing the literature on leadership and nursing curriculum revealed several recent attempts to engage students in active learning experiences for leadership development. In a critical review of research on leadership curricula in undergraduate nursing, Morrow (2015) included 13 related studies. A variety of active learning strategies designed to build leadership behaviours were used, including reflection assignments, peer learning, exposure to interprofessional teams, and organizational partnerships. A majority of active learning experiences were single events incorporated into a leadership theory course or added to a medical-surgical clinical. Morrow (2015) identified a need for research on teaching strategies that expose students to leadership on the broader organizational level, account for diversity of student backgrounds, and include experiential learning.

Several published studies describe clinical experiences with a leadership focus (Demeh \& Rosengren, 2015; Galuska, 2015; Lekan, Corazzini, Gilliss, \& Bailey, 2011; Schoenfelder \& Valde, 2009) or service learning experiences (Foli, Braswell, Kirkpatrick, \& Lim, 2014; Groh, Stallwood, \& Daniels, 2011). White and Walrath (2008) describe a leadership fellowship within their program that includes mentorship by a nurse leader and completion of a quality improvement project. Waite, McKinney, Smith-Glasglow, and Meloy (2014) describe a similar type of fellowship program for undergraduate students specifically designed to develop authentic leadership through critical pedagogy and action-oriented learning. Hendricks, Cope, and Harris (2010) describe a course that is completed as an optional extracurricular module in their program. There are also examples of efforts to thoroughly integrate leadership within the entire curriculum (Jones \& Sackett, 2009; Schoenfelder \& Valde, 2009; White \& Walrath, 2008). In addition, simulation-based learning (SBL) has been explored as a teaching strategy for leadership education. SBL strategies used include low-fidelity in-class events (Pollard \& Wild, 2014), hifidelity events (Kilgore, Goodwin, \& Harding, 2013; Thomas, Hodson-Carlton, \& Ryan, 2011), use of standardized patients (Sharpnack, Goliat, \& Rogers, 2013), and virtual clinical courses (Miner Ross \& Crusoe, 2014).

\section{Course Design}

The Bachelor of Science in Nursing (BScN) program began in 2007 at a Canadian university in western Canada. The blueprint of the program had been designed two years earlier in 2005 with an edict for a senior consolidation clinical course to precede the final preceptorship. When the time came to design the course, the course team decided to stay abreast of trends in nursing education while being responsive to the needs of students transitioning to the graduate role in nursing. The hypothesis was that providing opportunities for exploration and application of theoretical knowledge related to complex adaptive systems and leadership would enhance 
professional identity formation in graduates. Similar to Gregory and Russell (2003), the course team believed that the seeds of leadership need to be present in nursing pre-licensure programs and require intentional nurturing for future growth.

\section{Pedagogical Framework}

An important vision that guided the development of the course was the desire to provide students with an opportunity to practice their leadership skills within the context of the "hard spots" of nursing practice. Doane and Varcoe (2015) describe these hard spots as areas of nursing practice that require relational capacity for connection through diversity and difference. For the new graduate, navigating these challenging situations requires access to tacit knowledge, an often unacknowledged but essential antecedent to the patterns of knowing (Zander, 2007) needed for effective socialization. Doane (2002) theorized that nurses' professional and moral identities are socially mediated, and contextual influences are not always recognized by nurses. The goal in developing this course was to provide students with opportunities to "try on" theoretical learning with critical reflection as a mechanism for advancing their personal and professional identities. Poutiatine and Connors (2012) refer to this as a process of formation and transformation in professional development. Formation is the process through which one connects with one's identity to understand better how that identity is manifest and acted on in certain situations (Poutiatine \& Connors, 2012). Creating learning experiences to integrate formation in nursing curricula is essential in the socialization of the neophyte practitioner when opportunities to foster congruence and authentic engagement with values identity and integrity are realized (Monteverde, 2014). Transformation builds on the process of formation, through which learners experience an actual restructuring of their worldview to create congruence between their previously held values and where they envision themselves in the future (Poutiatine \& Connors, 2012). Mezirow and Associates (2000) explained that this transformation leads to development of more inclusive, differentiated and personal perspectives that allow for flexible responses in a variety of contexts, all of which can be connected to essential qualities for leadership development and future proofing for the new graduate. While transformation is not achievable for all learners at any given time, Poutiatine and Connors (2012) argued that these processes are important for the integration of theoretical knowledge on leadership.

The process of formation and transformation is supported by transformational learning theory (TLT) and forms the pedagogical foundation used in our instructional course design. TLT was originally developed by Mezirow (2009) to describe adult learning processes through which shifts in beliefs and identity occur because of new information being integrated into pre-existing schemas (Taylor, 2009). Dirkx, Mezirow, and Cranton (2006) note that these shifts lead to "deep learning" that affect identity and perspective. Also applicable to our purposes is the expanded view of TLT affecting more than just the cognitive realm, but also creating an ontological shift in the learner's "state of being in the world," including their sense of agency and relatedness (Lange, 2004).

In TLT, formation and transformation is made possible by creating safe learning spaces, exposing learners to "disorienting dilemmas", and providing opportunities for critical reflection where meaning-making schemas can be challenged (Mezirow, 2009). The disorienting dilemma, first described by Mezirow (1991) and further explored by others (Cranton, 2006; Poutiatine \& Connors, 2012), is an event or experience that challenges a person's worldview. Often disorienting dilemmas are situations that challenge the narrow limits of a person's worldview, requiring a broadening or flexing of perspective. Making sense of the situation can serve as a 
catalyst for change, wherein the adult learner forms an identity shaped by a new worldview (Taylor, 2009). In the case where a person's worldview is broad and flexible enough to make sense of the situation, there is a deepening of current belief structures (Poutiatine \& Conners, 2012). In the case of our senior-level nursing students, they would either encounter situations that required them to question and expand on their meaning-making schema, or the situations would provide an opportunity for increased confidence in their ability to navigate ambiguity, both of which we considered important for leadership development. Poutiatine and Conners (2012) describe the work of both formation and transformation as being critical for developing leaders. The need for integrity is essential for authentic leadership and providing the learner with opportunities for connecting identity and integrity during professional development is paramount (Palmer, 1998; Poutiatine \& Conners, 2012).

\section{Instructional Design}

The course curriculum (see Table 1 for course description and learning outcomes) was spearheaded and developed by a group of tenured professors. A team of clinical and tenured faculty deliver the course in September and January of each academic year. The size of the teaching team varies with the number of students but averages 9-12 instructors per offering (1:8 faculty-to-student ratio). Many of the clinical faculty members have had experience in leadership roles in the past. We describe each element of the course in more detail below.

\section{Table 1 Course Description and Learning Outcomes}

\section{Course Description:}

Students consolidate knowledge and skills as they begin the transition to registered nursing practice. Clinical practice experiences are selected to maximize readiness to practice, develop confidence, and enable collaboration with interprofessional teams. Students integrate theories and knowledge related to nursing practice, ethics, leadership/followership, complexity science, and health care system trends. Students evaluate the influence of evidence, policy and legislation on decision-making practices in complex health systems using a solution-focused perspective. Students analyze relational capacity of self and others for leadership, conflict management, team building, and change management. Knowledge, assessment, critical inquiry, clinical judgment and best nursing practices are integrated.

Course Concepts include leadership theories, complexity science, change theory, team building, followership, conflict management, health care trends, health economics, political dynamics, scope of practice, safety, outcome evaluation, jurisprudence, and relational capacity.

This course, which comprises group conferences, labs, and faculty-guided clinical experiences, broadens knowledge and skills to maximize influence on patients/clients and nursing staff/health care team within a variety of settings. Students integrate knowledge and skills related to competent, safe, ethical and evidence-informed practice within professional nursing roles not previously experienced. Clinical learning experiences will focus on the professional roles of the registered nurse in influencing indirect and direct client care. 
Learning Outcomes:

Upon successful completion of this course, the student will be able to

- demonstrate caring behaviours, compassion and respect for individuals, families, coaches, peers, faculty, and interprofessional team members within differing social, cultural, economic and political contexts;

- appraise the competencies of self, coaches, peers, faculty, and other stakeholders in leadership/followership roles;

- communicate and collaborate in partnership with coaches, peers, faculty, clients, families, and interprofessional team members to implement and coordinate health care with efficient and effective use of resources;

- evaluate the impact of leadership/followership styles/models on stakeholders, including clients, within situational environments;

- appraise relational practice capacity of self and others within the complexities, challenges and competing obligations of interprofessional practice teams;

- anticipate the consequences of change on client and nurse outcomes, patient safety, and the health care system using the lens of complexity science;

- analyze and interpret relevant evidence/legislation in the examination of practice issues, making recommendations for resolution/reconciliation;

- demonstrate accountability, responsibility, critical inquiry, and a commitment to lifelong learning.

Clinical partnerships. Each student is paired with a leader/coach (must be a registered nurse as delineated by professional regulatory requirements) from a variety of clinical practice settings (i.e., hospitals, public health and home care agencies, government ministries, long-term care facilities, and other health care organizations). Coaches include individuals in leadership roles that indirectly influence client care and outcomes including unit supervisors, patient care managers, executive directors, and clinical nurse educators. While some of the coaches have some responsibilities for direct client care, the primary role is one of leadership and professional education. The coach plays a critical role in each student's success in the course. The coach guides the learning for the student by connecting them with valuable experiences and assisting them to complete a mutually agreed upon project through which students experience leadership in action. The term coach was specifically chosen over preceptor or mentor in order to capture both the guiding and evaluative role expected (Patwell \& Whitfield Seashore, 2006). Types of activities our students experience include observing and participating in interviews; attending report for the area/unit; observing the charge role; communicating with the interprofessional team; attending leadership level meetings; participating in patient rounds; attending education related meetings and orientations; debriefings with coaches related to telephone calls, emails, and other forms of agency communication; and participating in a myriad of experiences related to the coach's role responsibilities.

Individual students are required to lead a quality improvement project for the clinical agency in consultation with the coach and faculty instructor. Projects focus on change management and are tailored to meet an identified need of the coach in relation to the agency mission, vision, and values. Each student develops a project proposal (usually within the second week), implements the identified plan, and evaluates the outcome during the five-week time 
span. Faculty instructors are pivotal in facilitating the successful completion of projects. Essential faculty roles related to the project include keeping the projects manageable given the short time frame and grading the project proposal and evaluative components. Coaches have input into the student's leadership performance in realizing their project goals and in the dissemination of the project toward the end of the course (see Table 3 for a list of completed projects).

\section{Table 3 Project Examples}

PowerPoint Presentations:

- Effective leadership and teamwork practices for a surgical unit

- Results of a wellness survey for an emergency department of a hospital

- Infection control and hand washing (need to increase compliance with this practice)

- Radiation Therapy Induced Diarrhea presentation to residents, staff physicians, nurse practitioners, and nurses

\section{Literature Reviews:}

- Hospital discharge techniques for effective discharge from hospital

- Scope of practice for registered nurses placed in charge positions on a medical unit

- Appropriate age of circumcision of infants

- Back-to-work programs

- Protocols and teaching strategies/materials regarding vaginitis

Posters/Staff Education/Other:

- Personal directives for a medicine unit

- Bullying/horizontal violence in the workplace

- Diagnostic imaging guidelines for medical units

- Employee engagement strategies

- Implementation of family-centered care philosophy in pediatric publications (i.e., job vacancy advertisements, online design of mission statement and values section)

- How to write new policy and procedures - presented to the education department

- Environmental proposal to recycle eligible equipment, including a list to be provided to inpatient staff members about what items are eligible for recycling

- Development and dissemination of a patient education tool for the neuroendocrine department entitled Living with Neuroendocrine Tumors

- Hand hygiene audits, education sessions, and outcome presentations

- Design of a palliative care program folder with inspirational pictures and helpful unit content for families

- Comprehensive care overview sheet design and implementation for consistency and increased quality of care for each resident

- Education presentations on less-restraint initiative

- Chart audits

- Development of charts or checklists to enhance quality care and education 
Post conferences. Weekly post conferences are an integral part of the clinical experience. Students and faculty collaborate in leading discussions, providing a forum for reflection and discussion of individual observations and experiences where application of theoretical learning from the previous term in the practice setting are realized. Students within a small group often attend the same meetings with their respective coaches; this creates opportunities for different perspectives on issues to emerge, assisting students to experience complexity in the health care system.

Clinical conference seminars. Clinical conference seminars using a context-based learning approach $(\mathrm{CBL})$ are included once a week. CBL was selected as a pedagogical method that could enhance students' sense of salience, creative use of existing nursing knowledge, selfdirected learning, and team relational strategies (Benner, 2010; Paige \& Smith, 2013), all of which are critical to leadership development. The two scenarios used are designed to capture the moral decision-making and leadership challenges conceptualized as disorienting dilemmas which nurses often encounter in everyday nursing practice within complex health care systems (see Table 2 for scenario descriptions). Throughout clinical conference, faculty members support students with the CBL process and challenge them to take on leadership and follower roles within the group learning experience. As students take on various roles within the conferences, ongoing group-, peer- and self-evaluation are essential components of their individual performance throughout the course. Evaluation of student performance in the clinical agency and clinical conference seminar is a shared responsibility between faculty and students.

\section{Table 2 Clinical Case Scenarios \& Simulated Learning Experiences}

\section{Clinical Case Scenarios}

The two clinical case scenarios are designed to foster integration of concepts including but not limited to transitions to the graduate role, trends and issues in nursing, advocacy, complexity, ethical reasoning and decision making, diversity, communication, and leadership/followership.

Case Study 1 - Steve Tarmac: In this case study, students are presented with a client (Steve Tarmac) who is transitioning from a short-term rehabilitation setting to home. The client is well known to the home care team, who experienced challenges related to his expectations of care in the past. Students discuss the role of the registered nurse in providing leadership/followership through delegation, collaboration, and a variety of styles of communication to work with the client and members of the interprofessional health care team to address complex health challenges.

Case Study 2 - Marilyn Robbins: In this case study, students examine the role of a neophyte registered nurse (Marilyn Robbins) as she deals with the situation of a resident and her family member in a long-term care setting. The scenario focuses on the delegation of responsibility to unregulated health care workers in caring for the resident. Students discuss the role of the registered nurse in providing leadership/followership through delegation, collaboration and communication to develop strategies to address a family member's concern. The importance of teamwork is explored. 


\begin{abstract}
Simulated Learning Experiences
Simulated learning experiences (SLEs) integrate concepts related to leadership/followership, advocacy, delegation, communication, and clinical decision making related to a variety of situations that may be experienced in the role of the graduate registered nurse.

Orientation to Simulation Lab Experience - The SLE presents the learner with an overview of the pedagogy for the simulation lab component. The guidelines, purpose and premises for the labs are explored in an interactive style enabling students to engage to their fullest potential. Teaching strategies for SLEs are made explicit to engage learners as full partners in the learning process.

Home Care Nursing Team Meeting - The SLE presents learners with the challenge of preparing as a team of nursing staff for working with clients in a home care environment. This experience is designed to integrate concepts related to leadership, followership, communication, team building, professional boundaries, relational ethics, and clinical decision making.

Case Conference - The SLE provides learners with an opportunity to participate in a case conference by assuming the role of a registered nurse in a capacity/responsibility that is relevant to the Steve Tarmac case study. A standardized patient (actor) plays the role of the client. Each participant will be provided with information specific to his/her assigned role/responsibility and will be given an opportunity to participate in the case conference from that viewpoint. This experience is designed to integrate concepts related to interprofessional collaborative practice, communication, and clinical judgment.

Meaningful Conversations - The SLE presents the students with the opportunity to participate in a dialogue with a standardized patient (actor) regarding iAdvance Care Planning: Goals of Care Designation. Individual students engage in two separate conversations with the patient and the patient and a family member regarding the patient's decision to stop medical treatment in consultation with her physician. The focus of the experience is the use of therapeutic communication skills and relational practice when dealing with a challenging topic.

Team Intervention - The SLE provides students with the opportunity to examine clinical decision making in an unfolding scenario where a palliative client's physiological status rapidly deteriorates. A family member played by a standardized patient (actor) is present in the room. The experience focuses on interprofessional collaborative and relational practice, resource utilization, team building, interprofessional communication, and interprofessional collaboration.
\end{abstract}

Simulated learning experiences (SLEs). Simulation based learning (SBL) is a key pedagogical method used to provide students with opportunities to practice and respond to disorienting dilemmas situated within lab scenarios. Five SLEs were designed to build on each other in offering unique examples of challenges in a variety of contexts in order to enhance students' confidence in identifying the role of leadership within many realms of nursing work (see Table 2 for SLE descriptions). The SLEs are intentionally designed to allow for a variety of responses from students as they navigate disorienting situations. Students are asked to take on a professional role but to respond within the scenario as they actually would, using their own professional values and knowledge as a guide. While students experience SLEs throughout all 
years of the nursing program, the SLEs in this course shift the focus away from psychomotor skills and clinical decision making to experiences related to leadership and followership, moral agency, and relational practice. An orientation SLE is used to engage students as partners in learning with the guiding principles of TLT and SBL. The subsequent four SLEs present students with clinical situations in which teams and individuals need to problem solve, respond, and take action. All SLEs include preparatory reading, briefing and debriefing specific to course content on relational practice, team building, leadership, and reflexivity. Actors are used to portray patients, family members, or colleagues in each scenario. No formal evaluation was used other than feedback from peers and faculty during debriefing, based on both TLT and SBL principles; instead students could use their learning experience within the SLE as a focus for the final course reflection assignment. This decreased some of the traditional power present within studentfaculty relationships, creating a safe space for students to critically reflect on responses, results, and associated meaning schemas (Bornais, Foisy-Doll, \& Wyrostock, 2013; Taylor, 2009).

\section{Evaluation}

To date the course team has been focused on process evaluation, including seeking feedback from students, coaches, and faculty regarding the experience of the course. Through their feedback, our coaching partners have shown strong support for the philosophy of the course, the benefits of mutual knowledge exchange, and the recognized need for new graduates to participate as leaders in complex health systems. We have worked with coaches to redesign the coach feedback form to ensure its relevance and validity in the clinical setting. Interestingly, we have recruited a number of coaches to join our clinical teaching faculty when they discover how much they enjoy mentoring students. Ripple effects of the course have been felt across the program in response to informal feedback received from partnering agencies, faculty, and students. Many tenured and clinical faculty members request to teach the course each year. Faculty feedback has guided both project marking guide changes and faculty education session planning.

Student feedback has been predominantly positive related to the learning experiences with the coaches and lab. Students have reported the heavy workload of the course, which has resulted in modifications to the project expectations. Based on early feedback regarding students' feelings of safety in the lab, the team initiated several strategies to ensure that safety is consistently addressed by the process and flow of the lab. This evaluation has led to observation checklists for the hi-fidelity labs that focus faculty on the leadership concepts, actor coaching and script revisions, extended debriefing training for faculty, and the creation of the orientation lab.

\section{Challenges and Future Directions}

Designing a course that breaks from curricular tradition requires faculty who are able to also break from established norms of teaching and authentically engage in the course pedagogy. As other nurse educators have found, simply transitioning educators to a new instructional strategy without addressing the underlying beliefs of the educators regarding teaching and learning can lead to resistance and poor uptake of curricular redevelopment efforts (Paige \& Smith, 2013). The use of CBL and SBL approaches requires a shift from task and content to more conceptual and self-directed learning wherein faculty are encouraged to create space for learning to happen (Paige \& Smith, 2013; Parker \& Myrick, 2010). The conceptual elements of the course also required a change in faculty's beliefs about leadership and teamwork. Many of 
our clinical faculty had graduated from more traditional education programs with limited exposure to leadership theory and complexity science. Shifting views from the "timed served" mentality of nursing leadership and transactional management theory to the transformational leadership and followership theory was another challenge.

Authentic relationships are a cornerstone of TLT, as it encourages questioning, fosters open dialogue, and forms the basis for mutual meaning making (Taylor, 2009). Trust is necessary in order for students reveal where they are on the "edges of meaning" without worrying about judgment from faculty (Taylor, 2009). For TLT to be enacted, there was a need to bring awareness to the power dynamics between faculty and students. Students also played an important role as conduits for the formation of the relationship between the coach and faculty instructor. Empowering the students to take responsibility for their relationships with their coaches was an additional factor that promoted trust and disruption of power relations between faculty and students. Needless to say, uncertainty was common experience for most faculty, many of whom were used to being in the role of expert within clinical courses. Mentoring and faculty capacity building became paramount for the course team (Paige, Arora, Hernandez, \& Seymour, 2015).

Critical to the success of the course was the creation of partnerships between and among faculty teaching the course. This was achieved through active engagement of core clinical faculty in the creation of new labs, revision of the course evaluation tool, SLE coordination, course resource management, and process evaluation. Working with resistance was key to the evolution of the course. While resistance can be seen as a negative force that limits learning in some situations, it can also be viewed as an action that resists conformity and facilitates liberation from oppression (Hillock, 2013). The need to create intentional learning spaces for faculty became obvious very early in the course, and these spaces were built into the course preparatory meetings and weekly lab debriefings. Creating a climate of teamwork for faculty instructors who often felt overwhelmed with theoretical content they were trying to master was transformational for everyone involved in teaching the course.

Ongoing challenges include costs associated with the SLEs, keeping the clinical conference and SLEs current and renewed for both faculty and students, managing the complexities associated with ineffective coaches, and the training of actors to play the parts of patients and family members in the SLEs. Actor fatigue during long days in the simulation lab has been an ongoing concern. Actors find themselves wanting to deviate from the scripts after several encounters over the course of long days in the simulation lab. The popularity of the course creates its own set of challenges. The need to keep a core group of clinical and tenured faculty within the course is paramount from a content and pedagogical perspective. Orienting faculty new to the course takes time and draws on resources needed for ongoing evaluation and content renewal.

\section{Implications for Research}

Now that the course is well established, there is an urgent need to conduct future research to explore if and how the student experience in the course is transformative. Collection of evaluative data for all course components will assist with future course development. There is a need for this evaluation to contribute towards the existing knowledge on leadership development. Despite the number of creative teaching approaches emerging, a common definition and framework for leadership in nursing seems to be absent (Lemire, 2005; Watts \& Gordon, 2012). 
As outlined by Watts and Gordon (2012), leadership education strategies are in need of evaluation beyond the immediacy of the course and its effects on later practice. Plans are underway to study the influence of the course on graduate attitudes and career progression in the coming year. Another area of further research identified is to explore the synergistic effects of leadership development within the clinical partnerships.

\section{Conclusion}

The critical need for registered nurses to enact leadership within the complexity of everyday practice has been well established by key stakeholders (CASN, 2014; CNA, 2011). The ever evolving landscape of health care system design and delivery calls for graduates who are future-proofed and capable of working dynamically in multiple contexts and teams using a variety of approaches (Keighley, 2013). The development of leadership competence and the capacity for working within complexity can no longer be left as a future career development goal (Gregory \& Russell, 2003). Nursing education programs have a responsibility to address leadership entry-to-practice competencies head on. We urge educators to break from tradition by considering the provision of practice experiences that move beyond direct patient care. In our attempt to respond to these demands, we found TLT provided a relevant and appropriate framework to help guide the design of a unique and innovative clinical course for senior level undergraduate nursing students. Using creative pedagogy and collaboration, we have established a clinical course that provides students with the opportunity to solidify the formation of a professional identity that embodies leadership prior to transitioning to the graduate role. Our experience reifies TLT as a pedagogical framework for leadership development in nursing curricula and stresses the importance of building empowering partnerships to foster leadership development among students, faculty, and coaches. As we continue to realize our vision for leadership development in nursing curricula, determining the degree of engagement of our graduates in health care system design, advocacy, and stewardship is an important next step. 


\section{References}

American Association of Colleges of Nursing. (2008). The essentials of baccalaureate education for professional nursing practice. Washington, DC: Author.

Anthony, S. E., \& Landeen, J. (2009). Evolution of Canadian nurse curricula: A critical retrospective analysis of power and caring. International Journal of Nursing Education Scholarship, 6(1), Article 18.

Benner, P. (2010). Education nurses: A call for radical transformation. San Francisco, CA: Jossey-Bass.

Bornais, J., Foisy-Doll, C., \& Wyrostock, L., (2014). Transforming nursing education using simulation. In D. Gregory, C. Raymond-Seniuk, \& L. Patrick (Eds.) Fundamentals: Perspectives on the art and science of Canadian nursing (pp. 290-313). Philadelphia, PA: Wolters Kluwer.

Canadian Association of Schools of Nursing. (2014). National nursing education framework: Preliminary report. Ottawa, ON: Author.

Canadian Nurses Association (2009). The next decade: CNA's vision for nursing and health. Retrieved from http://www.cna-aiic.ca/en/advocacy/policy-support-tools/the-next-decade

Cranton, P. (2006). Understanding and promoting transformative learning: A guide for educators of adults. San Francisco, CA: Jossey-Bass.

Cummings, G. G., MacGregor, T., Davey, M., Lee, H., Wong, C. A., Lo, E., ... Stafford, E. (2010). Leadership styles and outcome patterns for the nursing workforce and work environment: A systematic review. International Journal of Nursing Studies, 47(3), 363385. doi:10.1016/j.ijnurstu.2009.08.006

Demeh, W., \& Rosengren, K. (2015). The visualization of clinical leadership in the content of nursing - a qualitative study of nursing students' experiences. Nurse Education Today, 35, 888-893. doi:10.1016/j.nedt.2015.02.020

Dirkx, J., Mezirow, J., \& Cranton, P. (2006). Musings and reflections on the meaning context and process of transformative learning: A dialogue between J. M. Dirkx and J. Mezirow. Journal of Transformative Education, 4, 123-139.

Doane, G. (2002). Am I still ethical? The socially mediated process of nurses' moral identity. Nursing Ethics, 9(6), 623-635. doi:10.1191/0969733002ne556oa

Doane, G. H., \& Varcoe, C. (2015). How to nurse: Relational inquiry with individuals and families in changing health and health care contexts. Philadelphia, PA: Wolters Kluwer Health/Lippincott Williams \& Wilkins.

Foli, K. J., Braswell, M., Kirkpatrick, J., \& Lim, E. (2014). Development of leadership behaviors in undergraduate nursing students: A service-learning approach. Nursing Education Perspectives, 35(2), 76-82. doi:10.5480/11-578.1

Galuska, L. A. (2015). Dedicated education units: Partnerships for building leadership competency. Journal of Nursing Education, 54(7), 385-388. doi:10.3928/0148483420150617-05 
Gregory, D. M., \& Russell, C. K. (2003). Reaping what we sow: Nursing education and leadership in Canada and the United States. Canadian Journal of Nursing Leadership, 16(1), 38-41. doi:10.12927/cjnl.2003.16241

Groh, C. J., Stallwood, L. G., \& Daniels, J. J. (2011). Service-learning in nursing education: Its impact on leadership and social justice. Nursing Education Perspectives, 32(6), 400-405. doi:10.5480/1536-5026-32.6.400

Hendricks, J. M., Cope, V., \& Harris, M. (2010). A leadership program in an undergraduate nursing course in Western Australia: Building leaders in our midst. Nurse Education Today, 30, 252-257. doi:10.1016/jnedt.2009.12.007.

Hewison, K., \& Morrell, A. (2013). Rhetoric in policy texts: The role of enthymeme in Darzi's review of the NHS. Policy and Politics, 41(1), 59-79. doi:10.1332/030557312X645801

Hillock, S. (2013). Understanding oppression: The use of metaphor. Critical Social Work, 14(2), 115-133. Retrieved from http://www1.uwindsor.ca/ criticalsocialwork/

Institute of Medicine. (2011). The future of nursing: Leading change, advancing health. Washington, DC: National Academies Press.

International Council of Nurses. (2015). Leadership for change. Background. Retrieved from http://leadership.icn.ch/lfc/background/

Jones, J. M., \& Sackett, K. (2009). Integrating leadership and management content across the curriculum: A 3 course approach. Nurse Educator, 34(5), 204-208. doi:10.1097/nne.0b013e3181b4c4c6

Keighley, T. (2013). Future proofing nursing education. In K. MacMillan (Ed.). Proceedings of a think tank on the future of undergraduate nursing education in Canada. Halifax, NS: Dalhousie University School of Nursing.

Kilgore, R. V., Goodwin, M. E., \& Harding, R. A. (2103). Adding context to a simulation module for leadership and management baccalaureate nursing students. Journal of Nursing Education and Practice, 3(9), 148-155. doi:10.5430/jnep.v3n9p148

Lange, E. (2004). Transformative and restorative learning: A vital dialectic for sustainable societies. Adult Education Quarterly, 54(2), 121-139. doi:10.1177/0741713603260276

Lekan, D. A., Corazzini, K. W., Gilliss, C. A., \& Bailey, D. E. (2011). Clinical leadership development in accelerated baccalaureate students: An education innovation. Journal of Professional Nursing, 27(4), 202-214.

Lemire, J. A. (2005). Preparing nurse leaders: a leadership education model. In H.R. Feldman \& M. J. Greenberg (Eds.), Educating nurses for leadership (pp. 3-15). New York, NY: Springer.

Leonard, M. W., \& Frankel, A. S. (2011). Role of effective teamwork and communication in delivering safe, high quality care. Mount Sinai Journal of Medicine, 78, 820-826. doi:10.1002/msj.20295

MacMillan, K. (Ed.) (2013). Proceedings of a think tank on the future of undergraduate nursing education in Canada. Halifax, NS: Dalhousie University School of Nursing. 
Mezirow, J. (1991). Transformative dimensions of adult learning. San Francisco, CA: JosseyBass.

Mezirow, J., \& Associates (2000). Learning as transformation: Critical perspectives on a theory in progress. San Francisco, CA: Jossey-Bass.

Mezirow, J. (2009). Transformative learning theory. In J. Mezirow \& E. Taylor (Eds.), Transformative learning in practice: Insights from community, workplace, and higher education (pp. 18-31). San Francisco, CA: Jossey-Bass.

Miner Ross, A., \& Crusoe, K. (2014). Creation of a virtual health system for leadership clinical experiences. Journal of Nursing Education, 53(12), 714-718. doi:10.3928/0148483420141120-03

Monteverde, S. (2014). Undergraduate healthcare ethics education, moral resilience and the role of ethical theories. Nursing Ethics, 21(4), 385-401. doi:10.1177/096973301350530

Morrow, K. J. (2015). Leadership curricula in nursing education: A critical literature review and gap analysis. Journal of Nursing Education 54(7), 367-371. doi:10.3928/0148483420150617-02

National Expert Commission. (2012). A nursing call to action. The health of our nation, the future of our health system [PDF]. Retrieved from http://www.cnaaiic.ca/ /media/cna/files/en/nec_report_e.pdf

Paige, J. T., Arora, S., Hernandez, G., \& Seymour, N. (2015). Debriefing 101: Training faculty to promote learning in simulation based training. American Journal of Surgery, 209, 126131. doi:10.1016/j.amjsurg.2014.05.034

Paige, J. B., \& Smith R. (2013). Nurse faculty experiences in problem-based learning: An interpretive phenomenologic analysis. Nursing Education Perspectives, 34(4), 233-238. doi:10.5480/1536-5026-34.4.233

Palmer, P. J. (1998). The courage to teach: Exploring the inner landscape of a teacher's life. San Francisco, CA: Jossey-Bass.

Parker, B., \& Myrick, F. (2010). Transformative learning as a context for human patient simulation. Journal of Nursing Education, 49(6), 326-332. doi:10.3928/0148483420100224-02

Patwell, B., \& Whitfield Seashore, E. (2006). Triple impact coaching: Use of self in the coaching process. Columbia, MD: Bingham House Books.

Pollard, C. L., \& Wild, C. (2014). Nursing leadership competencies: Low fidelity simulation as a teaching strategy. Nursing Education in Practice, 14(6), 620-626. doi:10.1016/j.nepr.2014.06.006

Poutiatine, M. I., \& Conners, D. A. (2012). The role of identity in transformational learning, teaching, and leading. New Directions for Teaching and Learning, 212(130), 67-75. doi:10.1002/tl.20018

Schoenfelder, D. P., \& Valde, J. G. (2009). Creative practicum, leadership experiences in rural settings. Nurse Educator, 34(1), 38-42. doi:10.1097/01.nne.0000343400.11448.b0 
Sharpnack, P. A., Goliat, L, \& Rogers, K. (2013). Using standardized patients to teach leadership competencies. Clinical Simulation in Nursing 9, e95-e102. doi:10.1016/j.ecns.2011.10.001

Taylor, E. (2009). Fostering transformative learning. In J. Mezirow \& E. Taylor (Eds.). Transformative learning in practice: Insights from community, workplace, and higher education (pp. 3-17). San Francisco, CA: Jossey-Bass.

Teamwork and Communication Working Group. (2011). Improving patient safety with effective teamwork and communication: Literature review needs assessment, evaluation of training tools and expert consultations. Edmonton, AB: Canadian Patient Safety Institute. Retrieved from http://www.patientsafetyinstitute.ca/en/toolsResources/teamworkCommunication/Docum ents/Canadian\%20Framework\%20for\%20Teamwork\%20and\%20Communications.pdf

Thomas, C., Hodson-Carlton, K., \& Ryan, M. (2011). Preparing nursing students in a leadership management course for the workplace through simulations. Clinical Simulation in Nursing, 7, e99-e104. doi:0.1016/j.ecns.2010.06.005

Waite, R., McKinney, N., Smith-Glasglow, M. E., \& Meloy, F. A. (2014). The embodiment of authentic leadership. Journal of Professional Nursing, 30, 282-291. doi:10.1016/j.profnurs.2013.11.004

Watts, C., \& Gordon, J. (2012). Leadership and pre-registration nurse education. Retrieved from http://www.williscommission.org.uk/_data/assets/pdf_file/0009/480087/ Leadership and pre-registration_nurse_education.pdf

White, K., \& Walrath, J. M. (2008). An innovative approach to safety and quality education. In M. H. Oermann (Ed.), Annual Review of Nursing Education, (Vol. 6, pp.65-82). New York, NY: Springer.

Zander, P. E. (2007). Ways of knowing in nursing: The historical evolution of a concept. Journal of Theory Construction \& Testing, 11(1), 7-11. 